\title{
Inspeção na ponte do setor Umuarama em Porto Nacional
}

As estruturas em concreto, principalmente as armadas, são o método construtivo mais utilizado no Brasil, indo desde simples moradias a monumentais obras civis como arranha-céus e grandes pontes espalhadas ao longo do país e do mundo. Em geral, estes tipos de estruturas são suscetíveis ao aparecimento de patologias ao longo de sua vida útil. Objetiva-se com este trabalho o estudo das patologias em concreto armado através de pesquisas na literatura e inspeção visual, tendente para a ponte de Porto Nacional Tocantins, situada no setor Umuarama. O objetivo deste estudo é identificar as manifestações patológicas presentes, mediante inspeção visual, registros fotográficos e literatura técnica. O mesmo visa o estudo e a apresentação das principais causas de patologias em concreto armado que obtém as seguintes problemáticas como erros construtivos, causas físicas e biológicas, inadequação ao ambiente, corrosão da armadura, fissuras e trincas, etc. As inspeções seguiram as diretrizes da NBR 9452 (2019) e o manual de inspeção de Pontes Rodoviárias (DNIT, 2004). Verificou-se que a ponte segundo o critério de classificação de condição de obras de artes especiais da NBR 9452 (2019) apresenta uma condição ruim, sendo atribuída a ela uma nota 2, o que torna necessário uma inspeção especial, mais detalhada.

Palavras-chave: Inspeção; Pontes; Concreto Armado.

\section{Inspection at the Umuarama sector bridge in Porto Nacional}

Concrete structures, especially armed ones, are the most widely used construction method in Brazil, ranging from simple houses to monumental civil works such as skyscrapers and large bridges spread across the country and the world. In general, these types of structures are susceptible to the appearance of pathologies throughout their useful life. The objective of this work is to study the pathologies in reinforced concrete through research in the literature and visual inspection, tending towards the bridge of Porto Nacional Tocantins, located in the Umuarama sector. The objective of this study is to identify the pathological manifestations present, through visual inspection, photographic records and technical literature. The same aims at the study and presentation of the main causes of reinforced concrete pathologies that obtain the following problems such as construction errors, physical and biological causes, inadequacy to the environment, corrosion of the reinforcement, cracks and cracks, etc. The inspections followed the guidelines of NBR 9452 (2019) and the inspection manual for Highway Bridges (DNIT, 2004). It was found that the bridge according to the condition classification criterion of works of special arts of NBR 9452 (2019) presents a bad condition, being assigned a grade 2 , which makes a more detailed special inspection necessary.

Keywords: Inspection; Bridges; Reinforced Concrete.

Topic: Engenharia de Estruturas

Reviewed anonymously in the process of blind peer.
Received: 19/12/2020

Approved: 11/03/2021
Douglas Freitas Augusto dos Santos

Instituto Tocantinense Presidente Antônio Carlos, Brasil

http://lattes.cnpq.br/6181125172616043

eng.prof.santos@gmail.com

Lucas Neres da Silva (iD)

Instituto Tocantinense Presidente Antônio Carlos, Brasil

http://lattes.cnpq.br/9587665226176952

http://orcid.org/0000-0001-8181-5313

lucasneres17@gmail.com
Referencing this:

SANTOS, D. F. A.; SILVA, L. N.. Inspeção na ponte do setor Umuarama em Porto Nacional. Engineering Sciences, v.9, n.1, p.125-137, 2021. DOI: http://doi.org/10.6008/CBPC2318-3055.2021.001.0013 


\section{INTRODUÇÃO}

As Pontes também conhecidas como Obras de Arte Especiais são destinadas a transposição de um obstáculo natural, por exemplo, rios, lagos, vales etc. Suas principais problemáticas estão ligadas a um projeto mau elaborado, erro de execução e falta de manutenção, reduzindo a vida útil e a deixando deficiente por razões estruturais.

Existem pontes de distintas idades, dimensionadas e projetadas de diversos critérios e solucionadas para suportar as cargas moveis crescentes. E durante a sua vida as estruturas estão suscetíveis ao aparecimento de patologias. Nesse contexto, esse conjunto de obras devem ser regulamente inspecionadas, para que sejam avaliadas a segurança, capacidade de carga e conforto aos usuários. As inspeções devem ser conduzidas de forma organizada e sistemática, além de ser feito por profissionais competentes e habilitados DNIT (2004).

Portanto, este trabalho tem por objetivo identificar as manifestações patológicas presentes na ponte sobre o Rio Tocantins, mediante inspeção visual e registros fotográficos seguindo as diretrizes da NBR 9452 (2016) e o manual de inspeção de Pontes Rodoviárias DNIT (2004). Desta forma foi constatado pontos críticos, tais como, fissuras e trincas, corrosão das armaduras, esmagamento do concreto, lixiviação, etc.

\section{REVISÃO TEÓRICA}

De forma que se possa assegurar o desempenho e o cumprimento da vida útil das $O A E$, devem ser realizados alguns métodos de manutenções preventivas das mesmas a fim de se ter o acompanhamento da vida útil de tais obras para que assim seja possível conseguir prevenir o surgimento de futuras manifestações patológicas e demais anomalias.

Para tanto, alguns tipos de inspeções devem ser realizados ao longo de sua vida útil; estes métodos baseiam-se na coleta de dados com as características que demarquem a vida útil da OAE; essas coletas devem ser realizadas a partir de visitas técnicas e da recuperação de históricos da obra em seus vários âmbitos. Dessa forma este trabalho usará como base a diretrizes da NBR 9452 (2019) e Manual de inspeção de Pontes Rodoviárias DNIT (2004).

\section{Tipos de Inspeções Realizadas em Obras de Arte Especial (OAE)}

Os diversos procedimentos de inspeção a serem citados a seguir, possuem a finalidade de avaliar, verificar e manter integra uma OAE ao longo do seu tempo de utilização em relação a sua estrutura, funcionalidade e durabilidade cada tipo de inspeção deve ser realizado conforme a necessidade encontrada.

\section{Inspeção Cadastral}

A NBR 9452 (2019) diz que está inspeção deve ser realizada após a conclusão da execução de uma $\mathrm{OAE}$, ou quando forem realizadas mudança em sua estrutura ou ainda integrado um sistema de monitoramento e acompanhamento viário, após realizada esta inspeção, serão evidenciados em relatório de 
vistoria as eventuais anomalias e deficiências encontradas na estrutura que então será classificada; a partir desta classificação determinar-se-á a periodicidade e quais os tipos de inspeções serão necessárias para sua manutenção.

Pelo manual de inspeção de Pontes Rodoviárias DNIT (2004), o mesmo conceito é empregado, porém ele evidencia aspectos estruturais e os distribui conforme suas características nos demais tipos de vistorias que contempla em seu escopo.

\section{Inspeção Rotineira}

De forma que se possa manter a integridade de uma OAE, manutenções periódicas e preventivas devem ser realizadas; essas manutenções são precedidas pela Inspeção Rotineira.

O manual de inspeção de Pontes Rodoviárias DNIT (2004) e a NBR 9452 (2019) tratam a respeito desta inspeção de acompanhamento periódico. Nesta, deve-se verificar a possível evolução das anomalias observadas em inspeções anteriores ou a eficácia até então das medidas corretivas aplicadas anteriormente. A NBR 9452 (2019) estipula prazo máximo de um ano para realização de uma inspeção rotineira, sendo assim um pouco menos flexível que o manual do DNIT que estipula prazo máximo de dois anos para a realização de uma inspeção rotineira.

Estes tipos de inspeções são geralmente do tipo visual e realizadas em determinados trechos de interesse e os novos dados coletados são correlacionados na ficha cadastral onde são comparados e possíveis progressões de problemas são evidenciados. Em casos especiais onde circunstâncias alarmantes são encontradas ou em que o desenvolvimento de anomalias está acelerado far-se-á necessária a exigência de uma inspeção especial.

\section{Inspeção Especial}

A NBR 9452 (2019) diz que uma inspeção especial deve ser realizada com certa periodicidade compreendida a cada cinco anos, podendo em casos especiais ser postergada para até oito anos quando uma OAE apresentar boas condições de durabilidade e vida útil em uma sequência de inspeções rotineiras. Além disso, ela possibilita também que uma inspeção especial seja antecipada quando parâmetros estruturais e de durabilidade da estrutura apresentar classificação menor do que o esperado em uma inspeção rotineira por exemplo. Após realizada a inspeção especial, poder-se-á definir a melhor ação a ser tomada em relação a estrutura (Intervenção, Reestruturação e Demolição).

O manual de inspeção de Pontes Rodoviárias DNIT (2004) diz que esta é uma inspeção mais precisa e detalhada que uma inspeção rotineira na qual deve-se evidenciar em seu relatório todas as anomalias, e possíveis terapias cabíveis para correção do problema.

Temos então em ambas que a inspeção especial é uma verificação por sobremodo, bem mais criteriosa que os demais tipos de inspeções anteriormente citadas. Assim constata-se que ambas as normas descrevem a inspeção especial como sendo uma vistoria detalhada e minuciosa na qual avalia-se a verdadeira condição da OAE; este processo deve ser realizado com equipamentos especializados, com a utilização de 
testes realizados em laboratório de amostras coletadas na estrutura. Todos os dados encontrados devem estar relacionados com registros fotográficos e o correto preenchimento do relatório elaborado juntamente com um laudo com suas respectivas terapêuticas, tudo isso somado a gráficos e diagnóstico bem como seu devido prognóstico da estrutura como um todo para uma futura intervenção ou reestruturação da OAE.

\section{Inspeção extraordinária}

Neste caso, tanto a NBR 9452 (2016) quanto o manual de inspeção de Pontes Rodoviárias DNIT (2004) concordam que este tipo de inspeção, é como seu próprio nome diz "Extraordinário" portanto não é programado e só ocorre quando em casos que necessitem de medidas emergenciais, referentes a ocorrência através da interferências humanas, ambientais, catástrofes da natureza, impactos de veículos ou mesmo em decorrência da necessidade de uma averiguação criteriosa em determinado ponto de interesse na OAE. O manual do DNIT enfatiza ainda que em detrimento do problema encontrado em relação ao tipo e tamanho de dano sofrido pela estrutura, pode ser requisitada a limitação da quantidade de veículos que transitam sobre a OAE bem como a magnitude da carga transportada por estes, ou ainda a interdição total da OAE para tal averiguação.

\section{Inspeção Intermediária}

Esta Inspeção apenas é especificada no manual de inspeção de Pontes Rodoviárias do DNIT (2004), que indica uma necessidade de se realizar uma inspeção a fim de monitorar uma suspeita ou já detectada anomalia em uma OAE em um ponto especifico de forma cuidadosa. Esta é, portanto, realizada mais frequentemente em tipos novos de estruturas ou um novo detalhe acrescentado à estrutura, porém ainda não testado anteriormente, que podem se encontrar mais susceptíveis a problemas em sua composição ou no conjunto como um todo que trabalhe junto com este detalhe. Outras normas até relatam de forma sucinta sobre o assunto, porém, não enfatizam tal inspeção.

\section{Classificação de Obras de Arte Especial (OAE)}

As obras de arte devem ser classificadas segundo os parâmetros estrutural, funcional e de durabilidade, de acordo com a gravidade dos problemas detectados durante a inspeção, respeitando as Normas Técnicas aplicáveis e a boa prática da engenharia. A classificação adotada está de acordo coma NBR 9452 (2019).

\section{Parâmetros Estruturais}

Os parâmetros estruturais são aqueles relacionados à segurança estrutural da obra de arte, ou seja, referentes à sua estabilidade e capacidade portante, sob o critério de seus estados de limites último e de serviço, recomendados pelas normas técnicas nacionais aplicáveis a cada caso. Sob o ponto de vista de prioridades de ações de recuperação, é frequente estes parâmetros serem o objeto de maior atenção, notadamente quando a obra apresenta sintomatologia já visualmente detectável de desempenho 
estruturalmente anômalo.

\section{Parâmetros Funcionais}

Para que uma obra de arte atenda, plenamente, aos objetivos para os quais foi desenvolvida, é necessário possuir os requisitos geométricos adequados como, por exemplo: visibilidade, declividade, gabaritos verticais e horizontais. Por parâmetros funcionais se entenda, portanto, aqueles relacionados diretamente aos fins da obra. Os parâmetros funcionais também devem levar em conta o conforto e a segurança do usuário, considerando, por exemplo, a integridade dos guarda-corpos, existência de depressões e/ou buracos na pista de rolamento e a sinalização.

\section{Parâmetros de Durabilidade}

Designam-se por parâmetros de durabilidade aquelas características diretamente associadas à vida útil da obra, ou seja, com o tempo estimado em que a estrutura deve cumprir suas funções em serviço. Deste modo, estes parâmetros estão vinculados à resistência da estrutura frente a ataques de agentes ambientais agressivos. Exemplificam-se como anomalias associadas à durabilidade, ausência de cobrimento de armadura, corrosão, fissuração excessiva, danos ao tratamento superficial (pintura, galvanização, etc.) e erosões nos taludes de encontros. A relevância dos problemas de durabilidade deve ser avaliada em conjunto com a agressividade do meio em que se situam, com o objetivo de inferir a velocidade de deterioração a eles associados.

\section{Notas de Classificação}

A classificação de uma obra de arte consiste da atribuição de uma nota de avaliação, variando de 1 até 5, correlacionada à sua condição, podendo ser excelente (5), boa (4), regular (3), ruim (2) ou crítica (1) (ABNT, 2019). A classificação deve seguir o estabelecido na Tabela 1.

Tabela 1: Classificação da condição da obra de arte segundo os parâmetros estrutural, funcional e de durabilidade.

\begin{tabular}{|c|c|c|c|c|}
\hline $\begin{array}{c}\text { Nota de } \\
\text { Classificação } \\
\end{array}$ & Condição & Caracterização Estrutural & $\begin{array}{c}\text { Caracterização } \\
\text { Funcional }\end{array}$ & $\begin{array}{c}\text { Caracterização de } \\
\text { Durabilidade }\end{array}$ \\
\hline 5 & Excelente & $\begin{array}{l}\text { A estrutura apresenta-se em condições } \\
\text { satisfatórias, apresentando defeitos } \\
\text { irrelevantes e isolados }\end{array}$ & $\begin{array}{l}\text { A obra de arte } \\
\text { apresenta segurança e } \\
\text { conforto aos usuários }\end{array}$ & $\begin{array}{l}\text { A obra de arte está em } \\
\text { perfeitas condições, devendo } \\
\text { ser prevista manutenção de } \\
\text { rotina. }\end{array}$ \\
\hline 4 & Boa & $\begin{array}{c}\text { A estrutura apresenta danos pequenos } \\
\text { e em áreas isoladas, sem comprometer } \\
\text { a segurança estrutural }\end{array}$ & $\begin{array}{c}\text { A obra de arte } \\
\text { apresenta pequenos } \\
\text { danos que não chegam } \\
\text { a causar perda redução } \\
\text { significativa de } \\
\text { desempenho, } \\
\text { desconforto ou } \\
\text { insegurança ao usuário }\end{array}$ & $\begin{array}{l}\text { A obra de arte apresenta } \\
\text { pequenas e poucas } \\
\quad \text { anomalias que } \\
\text { comprometam sua vida útil. } \\
\text { Estrutura em região de baixa } \\
\text { agressividade ambiental. }\end{array}$ \\
\hline 3 & Regular & $\begin{array}{l}\text { Há danos que podem vir a gerar alguma } \\
\text { deficiência estrutural, mas não há sinais } \\
\text { de comprometimento da estabilidade } \\
\text { da obra. Recomenda-se } \\
\text { acompanhamento dos problemas. } \\
\text { Intervenções podem ser necessárias a } \\
\text { médio prazo. }\end{array}$ & $\begin{array}{l}\text { A obra de arte } \\
\text { apresenta desconforto } \\
\text { ao usuário, com } \\
\text { defeitos que requerem } \\
\text { ações de médio prazo. }\end{array}$ & $\begin{array}{l}\text { A obra de arte apresenta } \\
\text { pequenas e poucas } \\
\text { anomalias, que } \\
\text { comprometam sua vida útil, } \\
\text { em regiões de moderada a } \\
\text { alta agressividade ambiental } \\
\text { ou apresenta moderadas à }\end{array}$ \\
\hline
\end{tabular}




\begin{tabular}{|c|c|c|c|c|}
\hline & & & & $\begin{array}{c}\text { muitas anomalias, mas a } \\
\text { estrutura está em região de } \\
\text { baixa agressividade } \\
\text { ambiental. }\end{array}$ \\
\hline 2 & Ruim & $\begin{array}{l}\text { Há danos que comprometem a } \\
\text { segurança da estrutura, porém SEM } \\
\text { risco iminente. Sua evolução pode levar } \\
\text { ao colapso estrutural. A obra de arte } \\
\text { necessita de intervenções significativa a } \\
\text { curto prazo }\end{array}$ & $\begin{array}{l}\text { A obra de arte com } \\
\text { funcionalidade } \\
\text { visivelmente } \\
\text { comprometida, com } \\
\text { risco de segurança ao } \\
\text { usuário, requerendo } \\
\text { intervenções de curto } \\
\text { prazo. }\end{array}$ & $\begin{array}{l}\text { A obra de arte apresenta } \\
\text { anomalias moderadas a } \\
\text { abundantes, que } \\
\text { comprometam sua vida útil, } \\
\text { em regiões de alta } \\
\text { agressividade ambiental. }\end{array}$ \\
\hline 1 & Crítica & $\begin{array}{l}\text { Há danos que geram grave insuficiência } \\
\text { estrutural. Há elementos estruturais em } \\
\text { estado crítico, com risco tangível de } \\
\text { colapso estrutural. A obra de arte } \\
\text { necessita de intervenção imediata, } \\
\text { podendo ser necessária restrição de } \\
\text { carga, interdição parcial ou total ao } \\
\text { tráfego e escoramento provisório, } \\
\text { associada a monitoramento por } \\
\text { instrumentalização, ou não. }\end{array}$ & $\begin{array}{c}\text { A obra de arte não } \\
\text { apresenta condições } \\
\text { funcionais de utilização }\end{array}$ & $\begin{array}{l}\text { A obra de arte encontra-se } \\
\text { em elevado grau de } \\
\text { deterioração, apontando } \\
\text { problema já de risco } \\
\text { estrutural e/ou funcional. }\end{array}$ \\
\hline
\end{tabular}

\section{METODOLOGIA}

O trabalho trata-se de um estudo qualitativo, utilizando critérios baseados em recomendações e normativas, sendo estas, a ABNT NBR 9452 (2019) e o manual de inspeções rodoviárias do DNIT (2004). Foram verificados possíveis danos a OAE através de inspeções visuais realizadas nos dias 24,25 e 26 de setembro de 2020, na ponte localizada na Rua Dom Alano, setor Jardim Umuarama da cidade de Porto Nacional - TO (ver Figura 1 e 2). Esta ponte possui uma extensão de 24,00 metros, seu sistema estrutural é de pontes em vigas, e se enquadra em pontes de vias não navegáveis. O fluxo de trânsito é considerável, devido ser uma via de acesso ao centro da cidade.

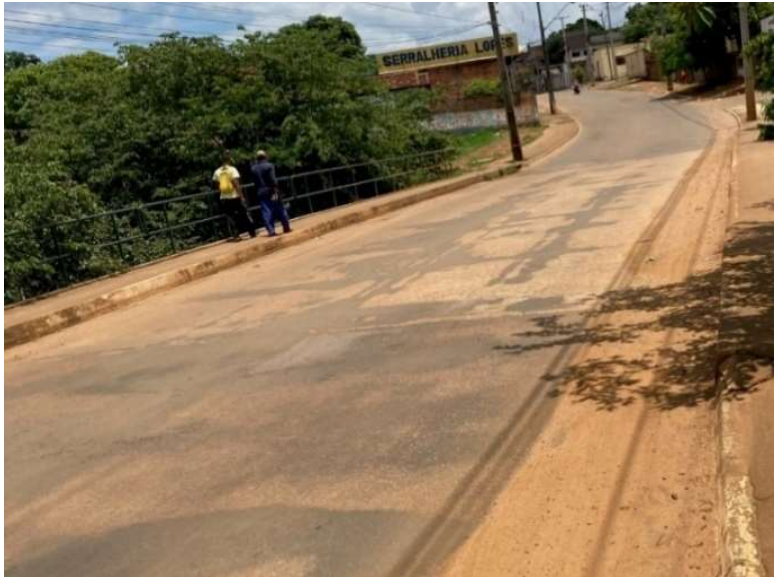

Figura 1: Vista frontal da Ponte.

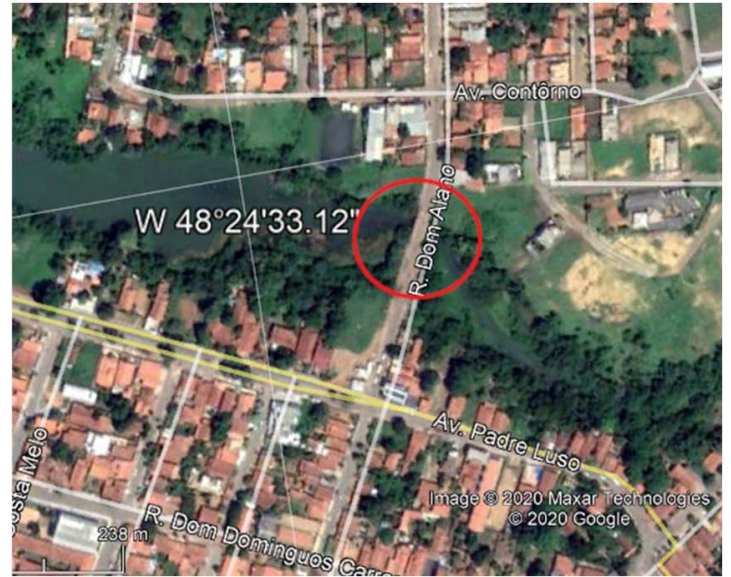

Figura 2: Localização da ponte. Fonte: Google Maps (2020)

Para o levantamento da situação da ponte foi utilizado os modelos de ficha de inspeção rotineira da NBR 9452 (2016). Este modelo é dividido em 3 partes, sendo a parte 1 dados cadastrais, como, identificação e localização, históricos das inspeções, descrição das intervenções executadas ou em andamento. Na parte 2 , registros destas manifestações patológicas, de forma descritiva. E por fim, na parte 3 foi determinado a classificação da OAE e os registros fotográficos realizados na inspeção. 


\section{RESULTADOS E DISCUSSÃO}

Diante da inspeção visual e levantamento de dados histórico da ponte, notou-se que a ponte de Porto Nacional localizada no setor Umuarama apresenta algumas manifestações patológicas que tem comprometido a sua vida útil. Os dados obtidos na ficha de inspeção e registro fotográfico estão descritos nos tópicos abaixo.

\section{Ficha de inspeção Rotineira}

Como descrito anteriormanete a ficha de inspeção é dividida em 3 partes, sendo a parte 1 composta por dados cadastrais, conforme apresentado na Tabela 2. Nesta tabela pode-se notar que o histórico das inspeções desta ponte não consta, gerando hipóteses de que nunca foi realizado uma inspeção. Entretanto este caso, é típico de pontes muito antigas, em que dados do projeto, cadastrais, registro de inspeções, manutenções, reparos ou reforços dificilmente são encontrados. Fato corroborado por não haver uma plataforma de controle destas OAEs, principalmente no que tange aos municípios, e também a mudança de governo e equipe técnica.

Tabela 2: Modelo de ficha de inspeção rotineira parte 1

\begin{tabular}{|c|c|c|}
\hline № & \multicolumn{2}{|c|}{ Ficha de Inspeção Rotineira } \\
\hline 1 & Inspeção Rotineira(ano):2020 & Código da obra de arte: 0020201 \\
\hline \multirow[t]{3}{*}{2} & Jurisdição (Órgão, Concessão ou outro): Municipal & Data de Inspeção: 27 de setembro \\
\hline & \multicolumn{2}{|c|}{ Parte I - Cadastro } \\
\hline & A - Identificação e localização & \\
\hline 3 & Via e Município: Setor Umuarama/Porto Nacional & Sentido: Centro \\
\hline \multirow[t]{2}{*}{4} & Obra: Ponte setor Umuarama & Localização (km e coordenadas geográficas): \\
\hline & B - Histórico das Inspeções & \\
\hline 5 & Inicial: Nada consta & Última Rotineira: Nada consta \\
\hline \multirow[t]{2}{*}{6} & Especial: Nada consta & \\
\hline & C - Descrição das intervenções executadas ou em andamento & \\
\hline 7 & Reparos: Nada consta & Material: Nada consta \\
\hline 8 & Alargamentos: Nada consta & \\
\hline 9 & Reforços: Nada consta & \\
\hline
\end{tabular}

Fonte: NBR 9452 (ABNT, 2019).

A Tabela 3 apresenta o registro de manifestações patológicas encontradas nos componentes da ponte. Dentre os apresentados pode-se verificar problemas na superestrutura, especificamente no tabuleiro, como, problemas de degradação, acumulo de pontos de umidade devido à ineficiência da drenagem. A longarina apresentou problemas de armadura exposta, fissuração provavelmente ocasionadas por conta da umidade e reação álcali agregado. Os pilares com problemas de lixiviação, ocasionando perda de resistência. Da mesma forma, pode-se encontrar problemas em outros componentes da ponte que foram descritos melhor na tabela e tópicos a seguir.

Tabela 3: Modelo de ficha de inspeção rotineira parte 2.

\begin{tabular}{|l|l|}
\hline № & \multicolumn{1}{|c|}{ Parte II - Registro de manifestações patológicas } \\
\hline & A - Elementos Estruturais \\
\hline 10 & $\begin{array}{l}\text { Superestrutura: Longarinas com problemas de fissuras, tabuleiros com fissuras, degradação por dilatação térmica e infiltração, } \\
\text { eflorescência. }\end{array}$ \\
\hline 11 & Mesoestrutura: Piares com degradação, exposição de armaduras, reação álcali-agregado \\
\hline 12 & Infraestrutura: Não foi possível constatar \\
\hline
\end{tabular}




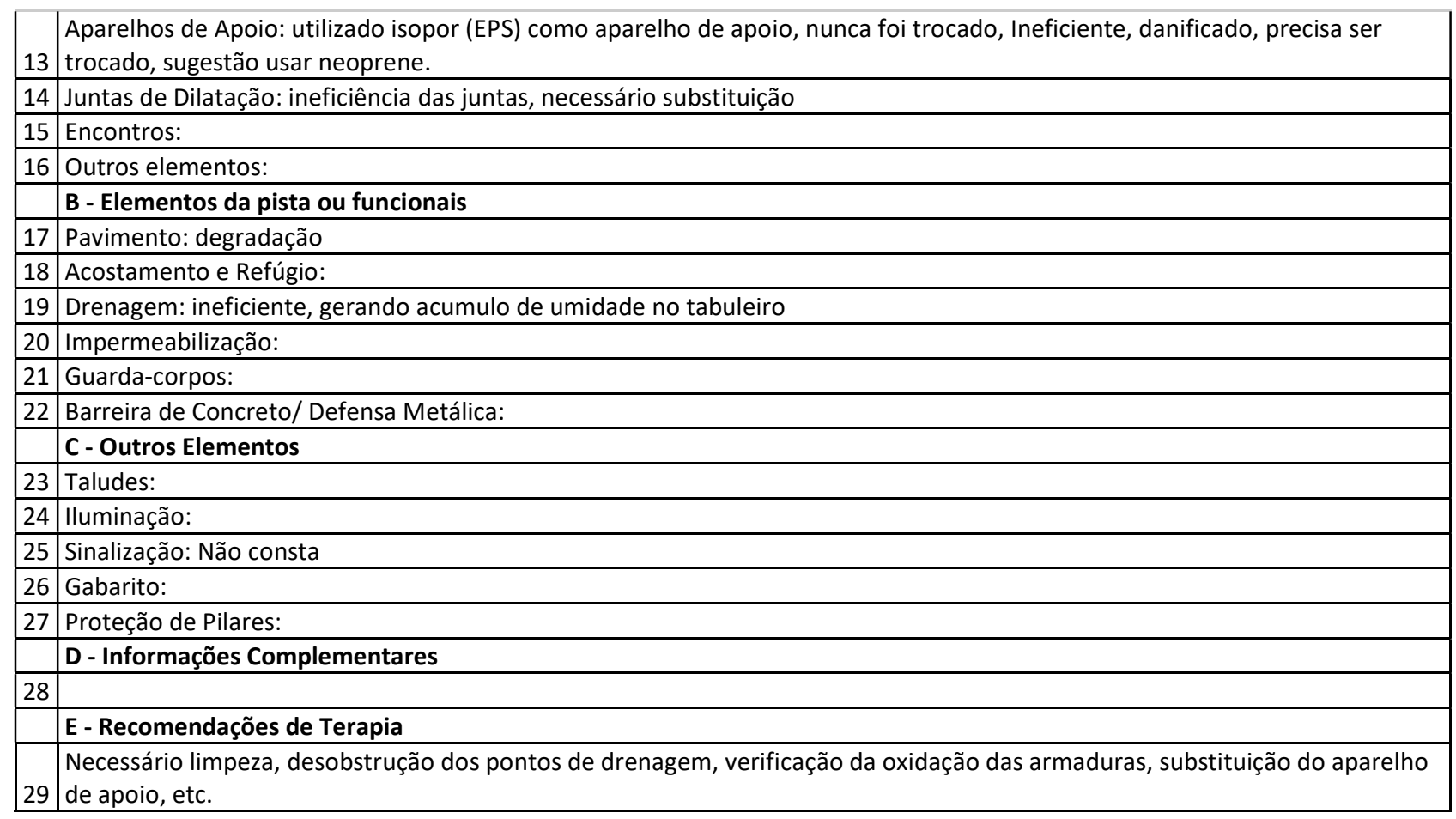

Fonte: NBR 9452 (ABNT, 2019).

A parte 3 trata-se do registro fotografico e a classificação dada pelo inspetor a obra vistoriada, podendo ser visto na Tabela 4, e suas manifestações patólogicas são descritas nos tópicos abaixo. Esta ponte, devido a problemas apresentados a alguns elementos estruturais, obteve classificação igual a 2 , sendo considerada pela NBR 9452 (2019), como uma ponte de classificação ruim. A classificação sempre será a menor nota obtida entre os elementos e parâmetros. Diante dessa nota, é necessário uma inspeção mais detalhada, para que possa ser verificado através de ensaios o real grau de degradação que a mesma se encontra, determinar a resistência do concreto, o nível de oxidação das barras de aço, classifica de forma mais detalhada cada componente, etc.

Tabela 4: Modelo de ficha de inspeção rotineira parte 3.

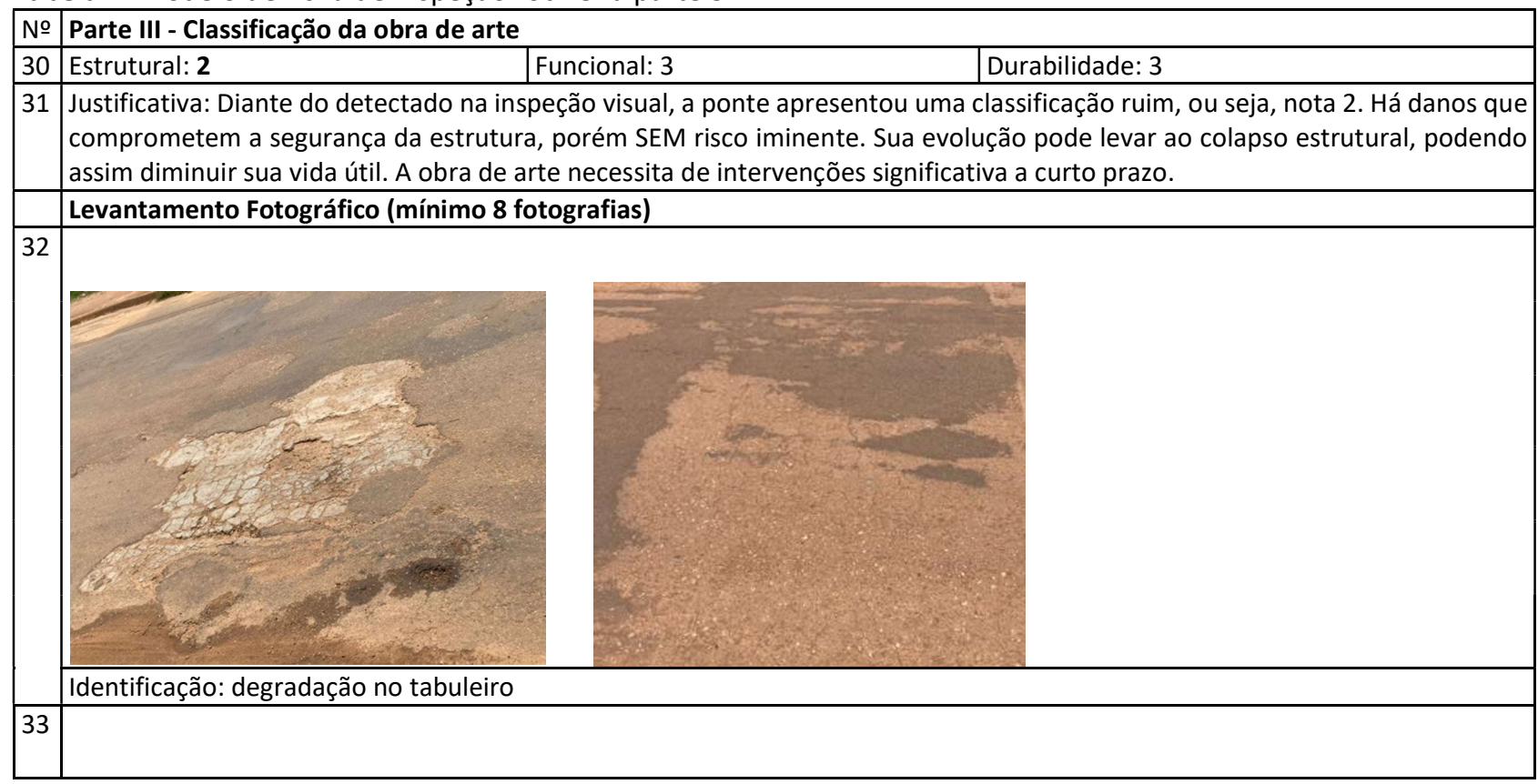




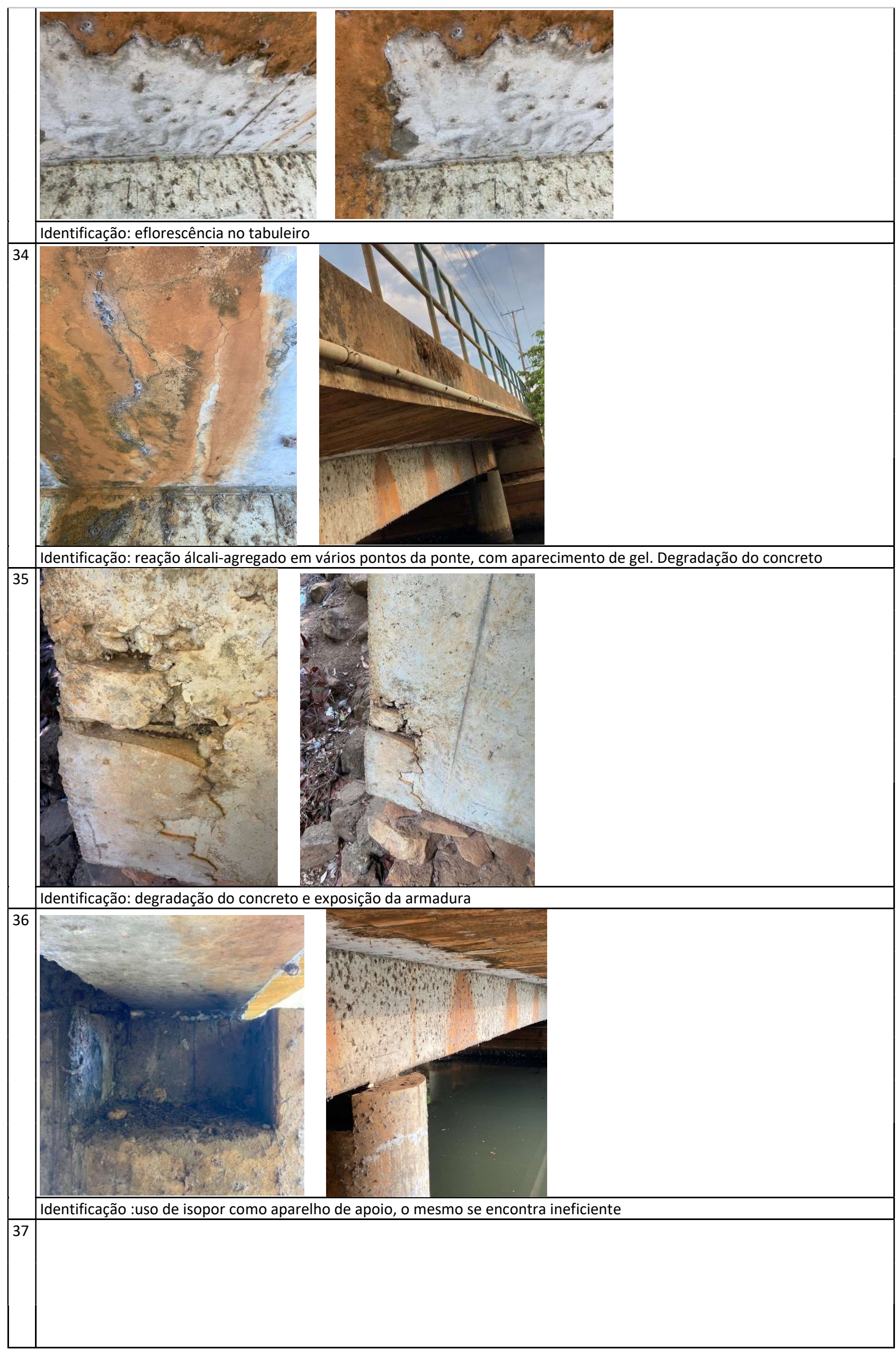




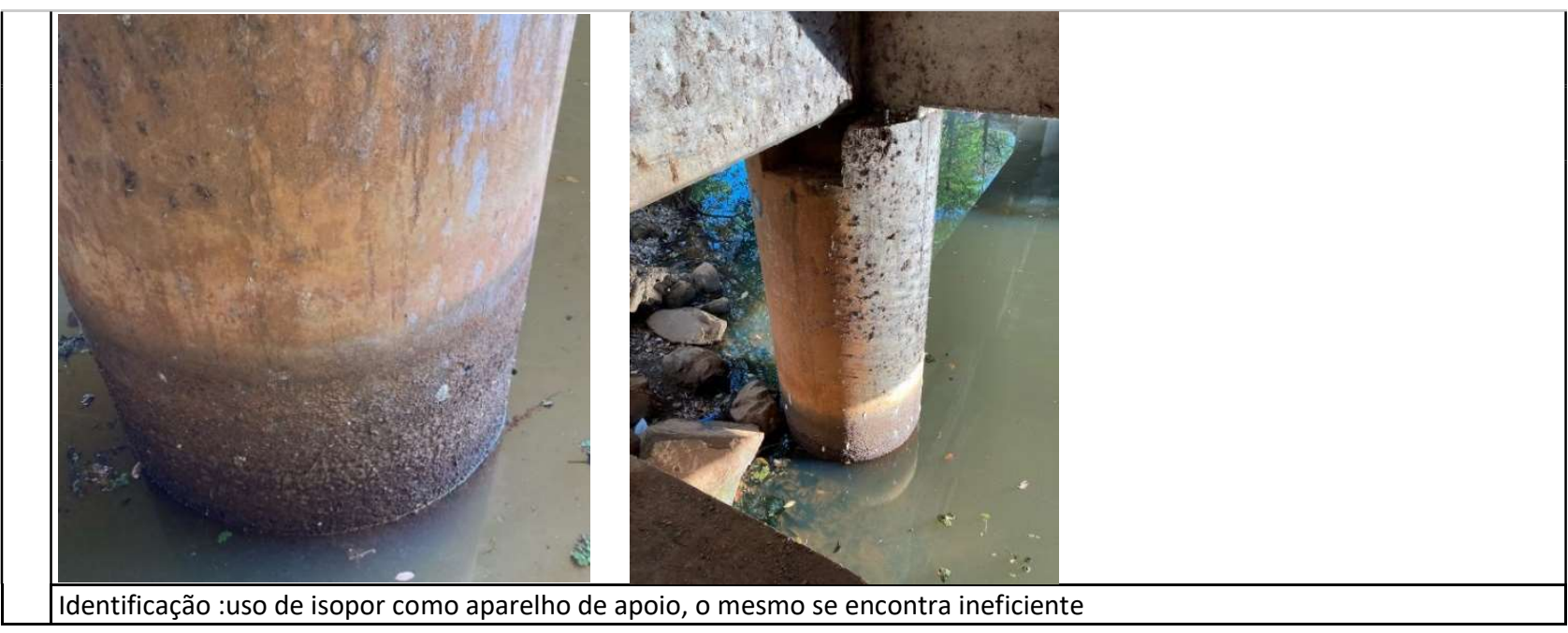

\section{Trincas e Fissuras}

Segundo a norma do DNIT 090/2006 as fissuras são classificadas como causas físicas da deterioração do concreto.

Foram observadas trincas e fissuras em praticamente toda a estrutura da ponte; essas fissuras podem ocorrer em consequência da fragilidade do concreto que continuamente está relacionado a fatores ambientais, como chuva causando excesso de umidade, insolação causando retração no concreto; por este motivo o concreto recebe uma tensão superior a tensão de tração que ele suporta motivando o aparecimento de fissuras na estrutura. A Figura 3 demonstra as fissuras no tabuleiro ocasionadas por retração.
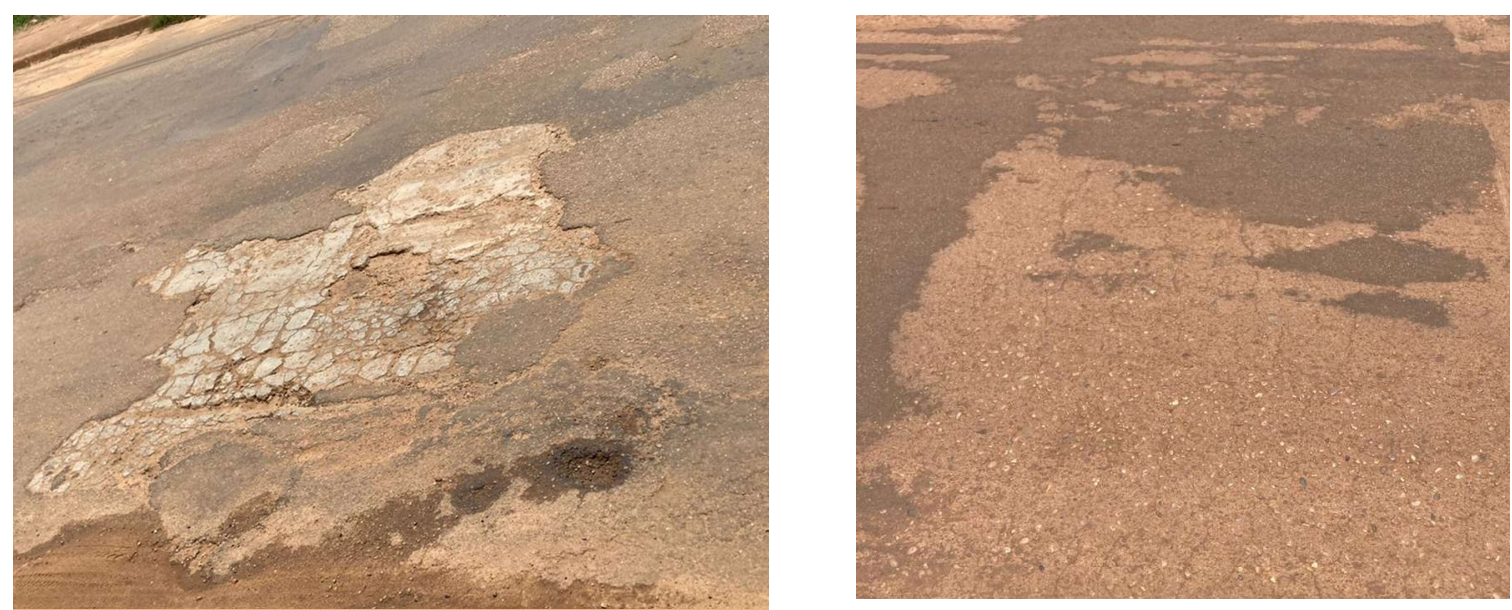

Figura 3: Fissuras e trincas no tabuleiro.

\section{Lixiviação}

Através da análise visual percebeu-se que em todos os pilares dessa ponte existe a deterioração por lixiviação na base dos pilares.

A lixiviação ocorre porque o cimento possui hidratação de suas moléculas, formando o hidróxido de cálcio, em contato com alta concentração de água esse ácido é dissolvido em sua estrutura e pode ser expelida para fora da superfície do concreto. Nesse processo ocorre a coloração que foi apresentado na Figura 4, sofrendo consequências na estrutura do concreto armado, como a perda da resistência mecânica do concreto. 


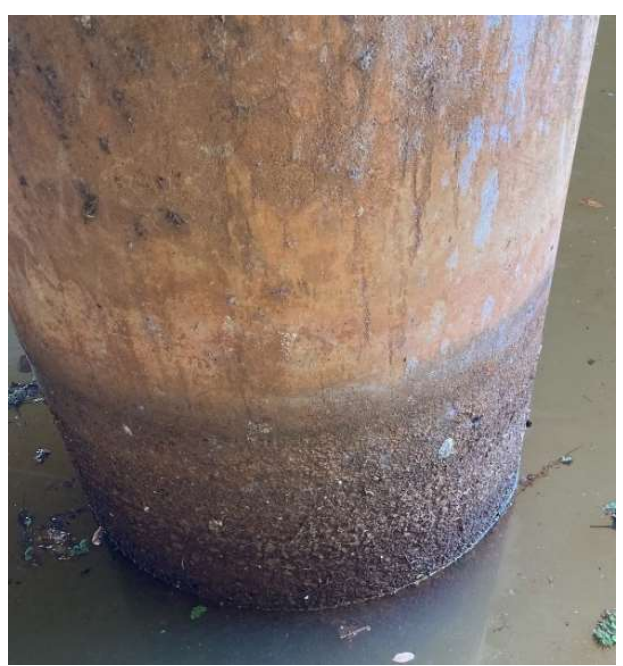

Figura 4: Lixiviação na base do pilar.

\section{Desagregação e Corrosão}

A desagregação está relacionada aos ataques químicos no concreto, provocando uma perca dos aglomerantes no cimento, deixando os agregados livres, ver Figura 5. As fissuras presentes terão uma expansão, realizando a entrada dos fenômenos externos e acontecerá um aumento no volume do concreto, desprendendo assim da armadura de aço devido à oxidação que a armadura sofrerá, deixando a mesma exposta (DNIT, 2004).

A diminuição da vida útil de uma estrutura em concreto armado, está direcionado ao aparecimento da corrosão. A intrusão de um agente externo irá ocorrer uma exposição da armadura, perdendo essa área que sofreu corrosão e que irá se estender por toda a estrutura obtendo uma perca considerável de área efetiva na seção transversal, em consequência a sua capacidade de suportar cargas será diminuída.

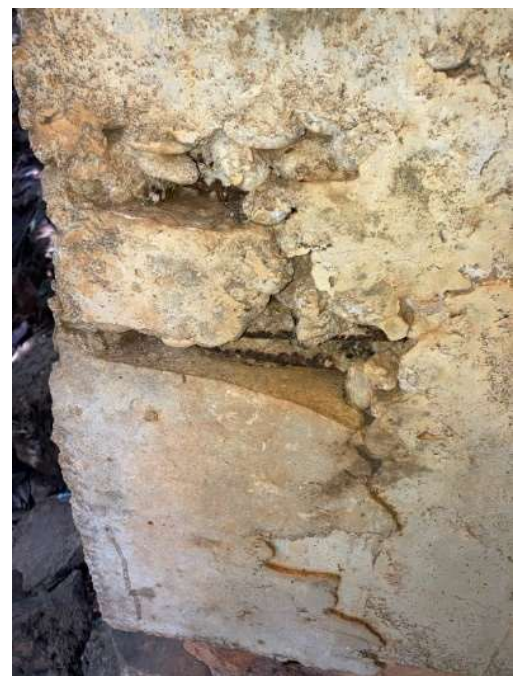

Figura 5: Desagregação e corrosão na estrutura.

\section{Reação álcali-agregado}

Presente entre as fissuras e trincas localizadas nas partes posteriores do tabuleiro, essa reação irá ocasionar consequentemente na degradação do concreto pode ocorrer o resultado de algumas reações prejudiciais, desse modo destaca-se a reação álcali-agregado (RAA) que nos tempos atuais já se tornaram 
menos frequentes. Ela se constitui de uma reação química entre os álcalis do cimento e nos minerais reativos presentes em alguns agregados (FELIX et al., 2017). Ocorrendo o aparecimento de trincas, devido à expansão do concreto que está sendo causada por conta do excesso de umidade, conforme Figura 6. Essa reação irá formar forma um gel, com o decorrer do tempo evoluirá de volume causando essa expansão e as trincas presentes (DNIT, 2004).

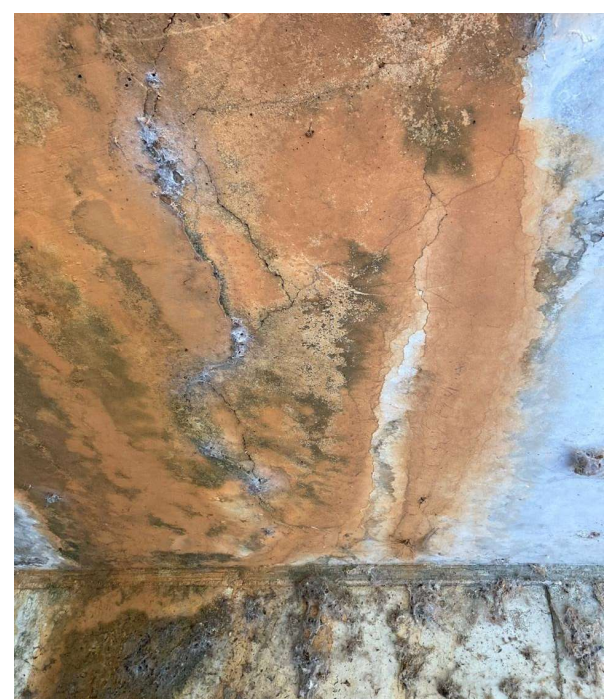

Figura 6: Reação Álcali Agregado na estrutura.

\section{Eflorescência}

Foi observado que a eflorescência está localizada na parte posterior do tabuleiro (Figura 7), ocorrendo em grande escala devido ao alto teor de humidade que essa estrutura está em contato, também é caracterizada pela formação de depósitos de sais na superfície de concreto, que se acumula devido à lixiviação causada por água de infiltração ou intempéries. Além de proporcionar um aspecto visual indesejado, o fenômeno pode ser prejudicial à integridade do concreto, sendo que o acúmulo de sais pode ser agressivo e provocar uma profunda desagregação.

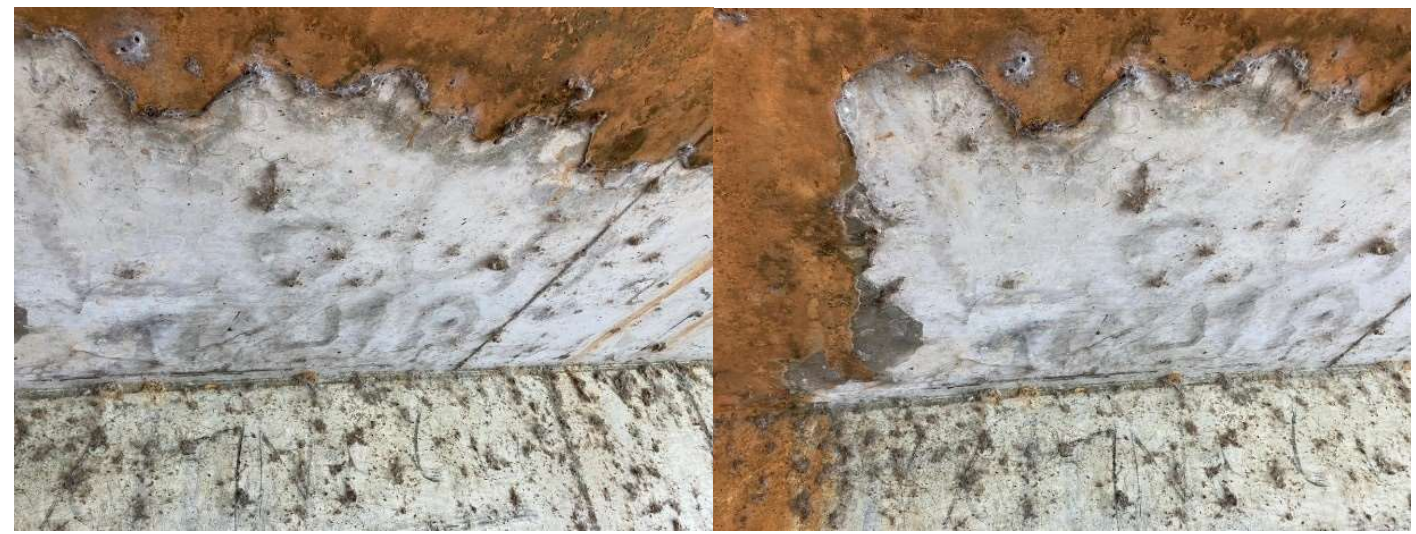

Figura 7: Eflorescência.

\section{Uso de Isopor na Junta de Dilatação}

O uso de EPS como apoio das longarinas pode ser observado na Figura 8. Essa prática comumente adotada na época que a ponte foi construída, entretanto, este aparelho de apoio deveria ter sido trocado 
para neoprene a tempos, e desta forma evitar problemas. Como mostra a figura 8 não foi realizado as devidas manutenções no material, com elevada presença de mofo, acúmulo de dejetos, sendo necessário a substituição.

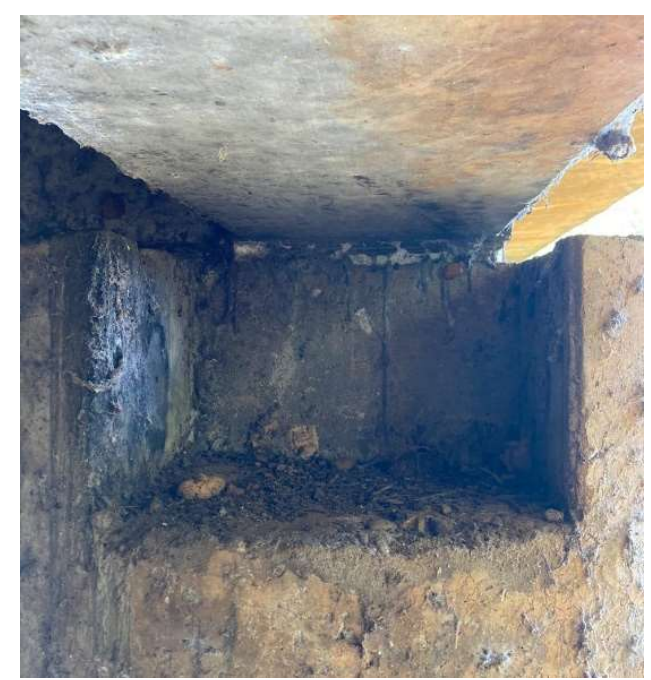

Figura 8: Uso de EPS como aparelho de apoio

\section{CONCLUSÕES}

Foi verificado que a ponte estudada, através de inspeções visuais apresentou manifestações patológicas comuns quando se tem a falta de inspeções. As inspeções são fundamentais, pois elas permitem compreender o estado em que a estrutura se encontra e desta forma propor manutenções, reparos ou até mesmo reforço. Entretanto, devido esta pesquisa ter realizado apenas inspeção visual não se pode chegar a dados conclusivos e propor adequações a ponte. $O$ ideal é com base nesses resultados realizar uma inspeção especial e assim realizar estudos mais detalhados, uso de equipamentos, ensaios não destrutivos e destrutivos, que poderão apresentar o nível de degradação, oxidação das armaduras e resistência do concreto atual. As manifestações patológicas se não forem tratadas poderão ocasionar danos maiores a ponte, comprometendo ainda mais a sua vida útil.

\section{REFERÊNCIAS}

ABNT. Associação Brasileira de Normas Técnicas. NBR 9452: Inspeção de pontes, viadutos e passarelas de concreto Procedimento. Rio de Janeiro: ABNT, 2019.

DNIT. Departamento Nacional de Infraestrutura de Transportes. Manual de inspeção de pontes rodoviárias. 2 ed. Rio de Janeiro: DNIT, 2004.
FELIX, E. F; POSTERLLI, M.; BALABUCH, T.; CARRAZEDO, R. Avaliação da durabilidade de uma viga de concreto armado sujeita à reação álcali-agregado. In: XIV CONGRESO LATINOAMERICANO DE PATOLOGÍA DE CONSTRUCCIÓN, 14; CONGRESO DE CONTROL DE CALIDAD EN LA CONSTRUCCIÓN, 16. Anais. 2017.

A CBPC - Companhia Brasileira de Produção Científica (CNPJ: 11.221.422/0001-03) detém os direitos materiais desta publicação. Os direitos referem-se à publicação do trabalho em qualquer parte do mundo, incluindo os direitos às renovações, expansões e disseminações da contribuição, bem como outros direitos subsidiários. Todos os trabalhos publicados eletronicamente poderão posteriormente ser publicados em coletâneas impressas sob coordenação da Sustenere Publishing, da Companhia Brasileira de Produção Científica e seus parceiros autorizados. Os (as) autores (as) preservam os direitos autorais, mas não têm permissão para a publicação da contribuição em outro meio, impresso ou digital, em português ou em tradução. 